\title{
Usos de la democracia,
}

el derecho penal y

los derechos humanos

como constructos de

dominación* / Uses of

Democracy, Criminal

Law and Human

Rights as Constructs

of Domination

* Recibido: 27 de noviembre de 2013. Aceptado: 9 de enero de 2014.

Tla-Melaua, revista de Ciencias Sociales. Facultad de Derecho y Ciencias Sociales. Benemérita Universidad Autónoma de Puebla, México / Issn: 1870-6916 / Nueva Época, Año 8 No 36, Abril / Septiembre 2014, Pp. 160-179. 
Alicia Hernández de Gante**

Carlos Antonio Moreno Sánchez****

\section{RESUMEN}

Este ensayo es una reflexión teórica sobre el capitalismo del siglo xxI. Señalamos algunos aspectos que consideramos sirven de sustento para desarrollar nuestro tema. Éstos se relacionan con ciertos mecanismos de control ideológico que sirven para mantener la protección del sistema económico. Enfatizamos que en la forma de Estado capitalista las relaciones entre sus diferentes esferas tienen el carácter peculiar de presentarse mediante la separación, es decir, escindidas, y en cierta medida, ajenas, como son la economía de la política. No obstante, pensamos que entre ellas no sólo existe articulación, sino que su carácter es inherente. Creemos también - y sin caer en reduccionismosque el régimen económico presenta cierta predominancia, no sólo sobre el sistema político, sino también sobre el sistema jurídico. En este sentido, áreas propias de la política, como la democracia y todos sus procesos, así como el derecho penal y parte de sus implicaciones, la defensa y protección de los derechos humanos, resultan ser tanto mecanismos sistémicos estructurales, como constructos ideológicos eficientes y eficaces para que el sistema dominante mantenga su hegemonía.

\section{PALABRAS CLAVE}

Sistema económico, derechos humanos, democracia, derecho penal, dominación.

\section{A B S T RAC T}

This paper is a theoretical reflection about capitalism of the Twenty-first Century. We note some aspects that we believe provide a basis to develop our theme. These are related to certain ideological control mechanisms that serve to maintain the protection of the economic system. We emphasize that in the form of capitalist state the relations between different spheres where they have the peculiar character presented by separation, namely, by way of divided societies, and to some extent, others, such as economics from politics. However, we think that between them, there is no link, but its nature is inherent. We also believe without falling into the economic system of reductionisms presents certain predominance, not only on the political system, but also on the legal system as well. In these regards, specific policy areas, including democracy and all its processes; as well as criminal law and some of its implications, the defense and protection of human rights happen to be both structural and systemic mechanisms, such as efficient and effective ideological constructs the dominant system to maintain its hegemony.

\section{KEYWORDS}

Economic system, human rights, democracy, criminal law, rule.

\footnotetext{
** Profesora investigadora en la Facultad de Derecho y Ciencias Sociales de la Benemérita Universidad Autónoma de Puebla (BUAP), México. (aliciahdegante@gmail.com)

*** Profesor investigador en la Facultad de Derecho y Ciencias Sociales de la Benemérita Universidad Autónoma de Puebla (BUAP), México. (morenojazz@yahoo.com.mx)
} 


\section{INTRODUCCIÓN ${ }^{1}$}

Actualmente, se percibe en la comunidad internacional que diversos organismos multilaterales, sumado a la firma de tratados de libre comercio que deben acatar los Estados miembro, es decir, los que son vinculantes con esas instancias, tienen injerencia en otros aspectos de la vida interna de los Estados. ${ }^{2}$ Con fines ilustrativos, retomemos el caso de México. Así tenemos que rubros como aumento de la productividad, mejora de la educación, reforma fiscal, acciones para generar mayor inclusión social y responsabilidad ambiental, en suma, un Estado más eficiente, forman parte de la agenda para México como parte de las recomendaciones emanadas en voz de Hasan Tuluy, vicepresidente del Banco Mundial para la Región de América Latina y el Caribe. ${ }^{3}$ En otro análisis, el Banco Interamericano de Desarrollo (BID), determinó que aproximadamente la mitad de la población en México se encuentra en situación de pobreza, fenómeno que se explica por el "bajo nivel de productividad en la economía, atribuible a factores

\footnotetext{
${ }^{1}$ La palabra constructo no está incluida en el Diccionario de la Lengua Española, sin embargo se usa y aplica en varias disciplinas. "Para la epistemología, se trata de un objeto conceptual o ideal que implica una clase de equivalencia con procesos cerebrales. Para la psicología, un constructo es una categoría descriptiva bipolar que permite a cada individuo organizar las experiencias y los datos de la realidad... Se conoce como constructo social, por otra parte, a la entidad que surge en un sistema construido por los integrantes de una sociedad". Véase: Definición de constructo - Qué es, Significado y Concepto. Disponible en: http://definicion.de/constructo/\#ixzz3AOSWrUtQ. [Fecha de consulta: 26 de julio de 2014]. Otras interpretaciones enfocadas a la investigación indican que constructo son “... conceptos científicos con los que se elaboran las teorías». Véase: Tamayo Tamayo, Mario. Diccionario de la investigación científica, México, Limusa, 2004, p. 29. En este trabajo, sin los reduccionismos definitorios, acordamos darle el sentido de entidades hipotéticas resultado de construcciones sociales en contextos histórico-políticos determinados, de tal suerte que la democracia, los derechos humanos y las formas jurídicas no sólo regulan la convivencia humana, sino que emergen como constructos ideológicos articulándose a los mecanismos y estructuras del poder tanto económico como político consustanciales de la forma capitalista.

${ }^{2}$ Para la región de América Latina, particularmente México, al menos mencionamos entre otros organismos: Fondo Monetario Internacional (FMI), Grupo del Banco Mundial; Organización para el Desarrollo y Cooperación Económica (OCDE); Banco Interamericano de Desarrollo (BID); Comisión Económica para América Latina y el Caribe (CEPAL).

3 "Foro México 2013. Políticas Públicas para un Desarrollo Incluyente", Ciudad de México, 9 y 10 de enero del 2013. La organización del Foro estuvo a cargo del BID, el Banco Mundial, la cEPAL y la ocDE, junto con el Gobierno de la República.
} 
como: informalidad, acceso al financiamiento, poca competencia y falta de apertura a la inversión internacional en algunos mercados de insumos claves"; " situaciones que deben ser atendidas conforme a las prioridades sectoriales y la consideración de los principales riesgos que el BID detectó en el marco del financiamiento 2013-2018 para México.

Introducir el discurso democrático también ha sido uno de los apalancamientos que utilizan los países económicamente dominantes y los organismos internacionales. Ante la necesidad de la modernización del Estado como parte de un proceso de reforma política que busque consolidar el Estado de derecho y la gobernabilidad democrática, se insta a la creación de diseños institucionales acorde con los tiempos. Tenemos así, que el BID recomienda a sus 48 países miembro, optimizar su sistema democrático, garantizar el Estado de derecho, realizar reformas al sistema judicial y, por ende, proteger los derechos humanos; mejorar la interacción entre Estado, mercado y sociedad; más, transparentar y eficientar la administración y gestión pública. ${ }^{5}$

Estas acciones, llevadas a cabo conforme a un pleno Estado de derecho, se espera, redituarían en beneficio de las poblaciones. Pero la realidad es otra, ya que en nombre de la democracia, de la aplicación del derecho penal y de la protección de los derechos humanos se violentan constantemente las garantías y los derechos fundamentales. Tenemos ejemplos recientes de que el derecho penal se ha encargado de controlar las protestas sociales mundiales, mediante la criminalización de los antagonistas del sistema capitalista-neoliberal. También la supuesta defensa de los derechos humanos y la democracia han justificado intervenciones genocidas hacia sociedades "desviadas" con el único fin de mantener y reproducir el sistema capitalista con los argumentos de que "el efecto de los esfuerzos militares será llevar la «democracia» a los pueblos que no la tienen[...] lo cual redundará en su propio beneficio, aun cuando en el corto plazo sufran todas las consecuencias del conflicto bélico y la dominación", 6 como ha ocurrido en algunas naciones de la comunidad internacional. "Los conceptos de derechos humanos y democracia, la superioridad de la civilización occidental por estar fundada en valores y verdades universales y la irremediable sumisión al «mercado» se nos presentan a todos como ideas incontrovertibles". ${ }^{7}$

\footnotetext{
${ }^{4}$ Documento del Banco Interamericano de Desarrollo, México. Estrategia del BID con el País, 20132018, Resumen Ejecutivo, noviembre 2013, s/p.

${ }^{5}$ Banco Interamericano de Desarrollo, Modernización del Estado, Washington D.C., Documento de Estrategia, julio 2013.

${ }^{6}$ Wallerstein, Immanuel, Universalismo europeo. El discurso del poder, México, Siglo XXI Editores, 2007, p. 95.

${ }^{7}$ Ibid., p. 13.
} 
Este es el contexto del problema en el cual se desarrolla este ensayo. En este sentido nos preguntamos: ¿Cuáles serán los mecanismos que utiliza el Estado como constructos de dominación? Al responder, nuestra aportación busca, mediante análisis, encontrar algunos elementos de tensión entre el discurso estatal, de corte neoliberal, que afirma que en aras de la democracia y de la libertad, los derechos humanos se protegen constitucional y legalmente así como, los derechos fundamentales por la justa administración y aplicación de la justicia mediante el sistema penal. Metodológicamente, partimos de una visión global que muestra las características de algunos preceptos que rigen al neoliberalismo, así como el papel que tiene hoy día el Estado, resultado de esta forma civilizatoria que marca los principios de la economía y de las formas de gobierno identificadas con la democracia, de tal forma que genera estructuras que reproducen el sistema político-económico. El objetivo de partir de este marco global es identificar el sustento jurídico que se proporciona mediante el Estado de derecho para la protección y defensa de los derechos humanos, legislaciones e instituciones que solo tienen sentido en los espacios de la democracia, pero que, no obstante, se utilizan como mecanismos de dominación, entre los cuales el derecho penal tiene un papel fundamental. Así, se integran las partes centrales de esta reflexión teórica.

\section{Mecanismos Sistémicos y ESTRUCTURALES}

Las exigencias de la globalización neoliberal han traído consigo la delimitación de las funciones del Estado; éstas, acorde con el movimiento del capital, y por supuesto, bajo lineamientos de los organismos financieros multilaterales que marcan las directrices de las políticas económicas. Cabe destacar que parte de las obligaciones del Estado y su forma de gobierno es administrar y aplicar los recursos públicos a cuestiones prioritarias: en el área de la economía, crear y mantener la estabilidad macroeconómica; en el área social, dirigir los programas de protección social, cuidando su efectividad y bajo costo; y en el sistema penal, asegurar las tareas del orden y la justicia. ${ }^{8}$

No obstante, y muy al contrario de las opiniones que visualizan la desaparición del Estado por la preeminencia del mercado, o incluso, lo que se denominó Estado mínimo, ${ }^{9}$ más acorde con la aparente falta de protagonismo en la vida pública, el Estado está más presente y fuerte que nunca. Su aparente desaparición la interpretamos como parte de la crisis que actualmente presenta por presiones de la economía y del mercado, sumado a la creciente

\footnotetext{
${ }^{8}$ Desde que se aplicó el Programa de Ajuste Estructural para América Latina, se perfilaron los lineamientos del nuevo tipo de Estado. Consúltese: Fondo Monetario Internacional. Perspectivas de la económico mundial. La globalización oportunidades y desafíos, Estudios Económicos y Financieros, FMI, mayo de 1997.

${ }^{9}$ Nozick, Robert, Anarquía, Estado y Utopía, México, Fondo de Cultura Económica, 1990.
} 
pérdida de legitimidad de las estructuras estatales. "Los Estados son un elemento crucial en la capacidad de los capitalistas para acumular capital. Los Estados vuelven posibles los cuasimonopolios, que son la fuente de niveles importantes de utilidades". ${ }^{10}$

En las crisis económicas (independientemente de su origen, bancario, financiero, comercial), el gobierno, sustentado en la normatividad estatal, primero, para tratar amortiguar el debacle económico, se constituye en garante de empresas e instituciones mediante millonarios rescates para tratar de controlar el impacto en cadena de la economía mundial; segundo, modifica sus políticas económicas internas para adecuarlas a las "recomendaciones" de los organismos encargados de la economía mundial, sin importar los costes sociales. Tan es así, que el Estado interviene a favor de los grupos favorables a la globalización para fortalecer su posición en el mercado, es decir, los intereses del capital son resultado tanto de los mercados como de la gestión política del Estado; así, se sobreentiende que hoy más que nunca estamos en un mundo de Estados-nación bajo un sistema global estructurado en complejas relaciones de dominación y subordinación. ${ }^{11}$

Una de esas caras es la depredación que acusa el capitalismo como una espiral ascendente, la cual ha sido ampliamente documentada. No tendríamos que rastrear mucho para saber el constante aumento de pobreza en el mundo, así como la explotación de recursos naturales o la contaminación ambiental generada principalmente por países desarrollados. Hablamos no sólo de las voces críticas que constantemente denuncian y lanzan llamadas de alerta a la comunidad internacional, como son intelectuales, organismos e instituciones de ayuda humanitaria, nos referimos a organismos oficiales, principalmente agrupados a Naciones Unidas y a empresas privadas que permanentemente monitorean datos relacionados con indicadores de riesgos económicos, políticos y sociales en la mayoría de los países del mundo.

Por ejemplo, el reporte The Institute for Economics \& Peace de 2014 llega la conclusión que hoy en día tenemos un mundo más violento ${ }^{12}$; otros organismos, como el Banco Mundial, en colaboración con instituciones nacionales, organismos de desarrollo y sociedad civil, realiza desde hace dos décadas programas de seguimiento a la pobreza, evaluando periódicamente su alcance, causas y desigualdad en vastos territorios del planeta. ${ }^{13}$ Si realizamos un cruce de información de ambos organismos, éste nos muestra la tendencia entre la

\footnotetext{
${ }^{10}$ Wallerstein, Immanuel, La decadencia del poder estadounidense, México, Editores Independientes, 2005, p. 65.

${ }^{11}$ Guillen retoma ideas de C. Vila y de E. Meiksins Wood entre otros autores para afirmar que los Estados-nación no desaparecen ni se ha creado un Estado suprancional, Véase: Guillen Romo, Arturo, Mito y realidad de la globalización neoliberal, México, M.A. Porrúa-Uam, 2007, pp. 140-142.

${ }^{12}$ Consúltese para este tema a: Vision of Humanity, "Index" Disponible en: http://www.visionofhumanity.org/\#/page/indexes/global-peace-index. [Fecha de consulta: 30 de julio de 2014].

${ }^{13}$ Banco Mundial, "Pobreza" Disponible en: http://datos.bancomundial.org/tema/pobreza. [Fecha de consulta: 30 de julio de 2014]. La taza de incidencia de pobreza es sobre la base de UsD 1.25 por día.
} 
articulación entre los índices de pobreza y los índices de violencia en varias regiones del mundo: Centro América, América del Sur, Asia Meridional y Oriental, pero, particularmente en la región de África al sur del Sahara.

A esta clase de informes/monitoreos se suman muchos otros cuyos resultados sirven de indicadores a las potencias hegemónicas para decidir toda clase de políticas, sean económicas, sanitarias, militares, etcétera. ${ }^{14}$ Esto viene a colación porque, efectivamente, en el derecho internacional público se estipulan los derechos y deberes de los Estados. Existen también otras normatividades que a propósito de las consecuencias que la depredación de las formas sistémicas y estructurales del capitalismo ocasionan en el orbe, se trata del derecho internacional sobre derechos humanos y del derecho internacional humanitario. Acorde a nuestro tema de estudio, los diferenciamos. En sentido estricto, el primero de ellos se aplica en condiciones de paz, mientras que el segundo en situaciones de hostilidades bélicas, guerras o conflictos ${ }^{15}$. Éste último representa apoyos importantes en situaciones de crisis humanitarias:

...aquellas situaciones en la que existe una excepcional y generalizada amenaza a la vida humana, la salud o la subsistencia. Tales crisis suelen aparecer dentro de una situación de desprotección previa donde una serie de factores preexistentes (pobreza, desigualdad, falta de acceso a servicios básicos), potenciados por el detonante de una catástrofe natural o humana, multiplican sus efectos destructivos. ${ }^{16}$

Retomamos la explicación de lo que significa una crisis humanitaria dado que en su nombre se aplica a discreción lo que Kouchner en 2004 denominó derecho de injerencia, que refiere a la intervención humanitaria. ${ }^{17}$ Esta acepción sólo tiene sentido en el derecho internacional, porque la injerencia humanitaria pone en tensión la soberanía del Estado y el derecho a interferir. Las intervenciones se dan por posibles conflictos que, acorde con Kouchner, pueden ser resueltos en la medida que se respete la soberanía que emane de personas con posición legal dentro del Estado, es decir, en un régimen democrático, pero se justificaría si fuere una dictadura o si se cometiesen actos de barbarie, circunstancia que no merece el respeto en absoluto de la comunidad internacional.

\footnotetext{
${ }^{14}$ Para un análisis de estos organismos, consúltese: Hernández de Gante, Alicia. Estados fallidos, violencia y poder, México, Gernika, 2011, pp. 151-197.

${ }^{15} \mathrm{El}$ derecho internacional humanitario nace propiamente con el Convenio de Ginebra en 1984.

${ }^{16}$ Aviñoa Ordoñez, Iris, et al. Alerta 2011!! Informe sobre conflictos, derechos humanos y construcción de la paz, Barcelona, Icaria Editorial - Escola de Cultura de Pau, 2011, p. 119.

${ }^{17}$ Wallerstein, Immanuel cita a Bernard Kouchner, quien acuñó el término «derecho de injerencia» Véase: El universalismo europeo. El discurso del poder... op. cit., particularmente el capítulo 1 "¿Injerencia en los derechos de quién? Valores universales vs. barbarie".
} 
En el análisis que hace Wallerstein, surgen otros cuestionamientos que van más allá del problema anterior sobre la soberanía. El primero refiere a los actos de barbarie que se comenten para liberar al pueblo, ¿quiénes son los bárbaros, los que dominaban o los que intervienen? o "¿Los países y los pueblos que emprenden intervenciones son también culpables de cometer actos de barbarie?". ${ }^{18}$ Wallerstein responde de manera afirmativa. Ejemplos recientes son la guerra de los Balcanes y la guerra contra Irak, que mostraron que la injerencia de los Estados interventores fue contradictoria sobre todo porque ambas intervenciones promovían la democracia, asociando el concepto mismo al control externo violento y a los factores negativos que la intervención conlleva.

El otro grave problema que surge es la obligación de castigar a los que comenten crímenes contra la humanidad, lógica que parece sencilla pero que en realidad genera más cuestionamientos tanto en el derecho interno como en los tribunales internacionales ¿Quién ha definido esas acciones como crímenes? "¿Quién tiene jurisdicción para castigar?”. ${ }^{19}$ Finalmente, Wallerstein se pregunta: ¿injerencia en los derechos de quién? Su respuesta:

...está dirigida al meollo de la estructura política y moral del moderno sistema-mundo. La intervención es, en la práctica, un derecho que se apropian los poderosos. Pero es un derecho difícil de legitimar y por ello está siempre sujeto a desafíos políticos y morales. Los interventores, cuando se les desafía, recurren siempre a la justificación moral: el derecho natural y el cristianismo en el siglo XVI, la misión civilizadora en el siglo XIX y los derechos humanos y la democracia a fines del siglo Xx y principios del XxI. ${ }^{20}$

Con este esbozo, se muestra cómo funcionan parte de los mecanismos y estructuras que permiten la permanencia del sistema político-económico. Los países de primer mundo han recurrido al constructo ideológico del derecho de injerencia para "guiar" convenientemente políticas económicas y jurídicas de los países subdesarrollados. Los argumentos tienen diversos nombres: civilización, modernización, crecimiento económico, desarrollo, progreso, etcétera; todos interpretados como expresiones de valores universales, incrustados en un supuesto derecho natural que utiliza lenguajes teológicos o derivados de una visión filosófica y secular del mundo, ${ }^{21}$ pero que definitivamente se constituyen en mecanismos de dominación ideológica.

\footnotetext{
${ }^{18}$ Ibid., p. 37.

${ }^{19}$ Ibid., p. 38.

${ }^{20}$ Ibid., p. 44.

${ }^{21}$ Ibid., pp. 15-16.
} 


\section{DERECHOS HUMANOS NEOLIBERALES}

Los derechos humanos tienen un fuerte sustento en el derecho internacional. ${ }^{22}$ Quizá de una forma más perceptible a partir de que se implantó como forma económica-política el sistema neoliberal. El nuevo liberalismo, las nuevas formas de acumulación económicas, aunado a formas de gobierno democráticas han puesto en el ius el complejo tema de los derechos humanos. Por ello, los derechos humanos tienen un sustento jurídico. No podría concebirse un régimen democrático sin un Estado de derecho que proteja a los individuos del abuso del poder.

A nivel de cada Estado, el Estado de derecho en esencia debe garantizar que el actuar de autoridades y funcionamiento de instituciones se rijan por la norma, aplicando y defendiendo derechos y libertades fundamentales de forma justa e imparcial. Así, el Estado de derecho se sustenta en cuatro puntos esenciales: 1) la división de poderes; 2) el imperio de la ley; 3) legalidad de la administración pública y del poder judicial; y 4) la protección de los derechos y libertades fundamentales de los ciudadanos. ${ }^{23}$ Queda entendido que es parte esencial del Estado de derecho la salvaguardia de los derechos humanos tanto constitucionalmente como por sus leyes secundarias.

Quizá un señalamiento más acotado sobre el Estado de derecho, particularmente respecto a la protección de los derechos y libertades fundamentales que mencionamos, refiera a las prohibiciones y obligaciones que en aras de la libertad se deben considerar. Así, Ferrajoli realiza una diferencia entre lo que denomina Estado de derecho liberal y Estado de derecho social, el primero referido esencialmente a las libertades, mientras que el segundo a la protección obligatoria del Estado en cuestiones de carácter social.

A diferencia de los derechos de libertad, que son derechos de (o facultades de comportamientos propios) a los que corresponden prohibiciones (o deberes públicos de no hacer), estos derechos, que podemos llamar «sociales» o también «materiales», son derechos a (o expectativas de comportamientos ajenos) a los que deberían corresponder obligaciones (o deberes públicos de hacer). La noción liberal de «estado de derecho» deber ser, en consecuencia, ampliada para incluir también la figura del estado vinculado por obligaciones además de,

\footnotetext{
${ }^{22}$ Mencionamos para nuestra región de América Latina la Oficina del Alto Comisionado para los Derechos Humanos de Naciones Unidas (OACDH) que junto al Consejo de Derechos Humanos conforman "órganos creados en virtud de tratados internacionales de derechos humanos, y compuestos por expertos independientes con el mandato de supervisar que los Estados partes en los tratados cumplan sus obligaciones". Suman un decena de órganos en el derecho internacional que a nivel de todos los Estados vigilan la aplicación de los tratados. Consúltese OACDH-ONU, octubre 2011.

${ }^{23}$ Haddad, Marcelo. “Quién gobierna en el Estado de derecho?” en Desde el Fondo, Cuadernillo Temático, Argentina, número 24, 2002.
} 
por prohibiciones. Diremos por consiguiente, que cuando un ordenamiento constitucional incorpora sólo prohibiciones, que requieren prestaciones negativas en garantía de los derechos de libertad, se le caracteriza como estado de derecho liberal; cuando por el contrario, incorpore también obligaciones, que requieren prestaciones positivas en garantía de derechos sociales, se le caracterizará como estado de derecho social. ${ }^{24}$

Bobbio, por su parte, afirma que "El problema de fondo relativo a los derechos humanos no es tanto el de justificarlos como el de protegerlos. Es un problema no filosófico, sino político". ${ }^{25}$ Sobre ello pensamos que efectivamente, su tutela exige considerar - aunado a las protecciones legales - la voluntad política de los gobernantes. Tratando de ir un poco más a fondo, tanto en la voluntad política como en el discurso que emite esa autoridad política, debemos considerar que el discurso de los derechos humanos sólo tendrá validez en determinado tiempo o momento histórico siempre y cuando sea reconocido, por lo que es importante utilizar adecuadamente un código lingüístico del discurso tomando en consideración la estructura ideológica que conforma a los sujetos sociales en cada momento histórico. ${ }^{26}$

Esto problematiza aún más fenómeno de los derechos humanos, particularmente por lo que hemos afirmado que constituyen un eje de dominación por el manejo ideológico que se realiza a través del discurso. "La ideología tiene que ver con el «discurso» más que con el «lenguaje»... Representa los puntos donde el poder incide en ciertas expresiones y se inscribe tácitamente en ellas... a la luz de ciertas luchas de poder centrales para la reproducción... de toda una forma de vida social". ${ }^{27}$ Tanto las ideologías dominantes como las de oposición utilizan mecanismos como la "unificación, identificación, espuria, naturalización, engaño, autoengaño, universalización y racionalización”. ${ }^{28}$

Realmente, tratar de definir la ideología per se y delimitar el impacto que tiene en la sociedad está fuera de este estudio, considerando que es un fenómeno que no está libre de conflictos y contradicciones. Sin embargo, afín a lo que hemos planteado, retomamos el sentido de la ideología como la finalidad de la construcción de una determinada realidad por medio de una

\footnotetext{
${ }^{24}$ Ferrajoli, Luigi, Derecho y razón. Teoría del garantismo penal, Madrid, Editorial Trotta, 1995, p. 861.

${ }^{25}$ Bobbio, Norberto. El tiempo de los derechos, Madrid, Editorial Sistema, 1991, p. 61.

${ }^{26}$ Consúltese a Saussure para el estudio de la lengua en un determinado periodo de tiempo y en su evolución a lo largo del tiempo. Saussure, Ferdinand, Curso de Lingüística General, México, Fontamara, 2008.

${ }^{27}$ Eagleton, Terry. Ideología. Una introducción, España, Paidós, 1997, p. 277.

${ }^{28}$ Eagleton advierte sobre las diferentes "concepciones esencialistas de la ideología: ante la posición historicista de que es la cosmovisión coherente de un «sujeto de clase»; ante la teoría que se segrega espontáneamente de las estructuras económicas de la sociedad; o ante la doctrina semiótica de qué significa «cierre discursivo». Todas estas perspectivas contienen un núcleo de verdad; pero tomadas aisladamente resultan parciales y fallidas", Ibid., p. 276.
} 
creencia codificada en el lenguaje que se trasmite por medio del discurso, implicando que la identidad del sujeto se logre por medio de la construcción de hechos ficticios o falsos, y la idiosincrasia en las personas se modifique por medio de la construcción de hechos que permiten la manipulación en la apreciación de lo real.

La apreciación y construcción de lo real la interpretamos en el sentido de Wallerstein como realidades fundamentales que marcan el ritmo para la definición de reglas en la dinámica funcional del sistema dominante y que éste ha creado a través del discurso más apropiado dándole funcionalidad en determinado contexto histórico, con el fin de que pueda ser comprendido, reconocido y validado por la sociedad de una época especifica. Estas realidades, en apreciación de Wallerstein, son: la división de trabajo; los patrones o ritmos cíclicos; la acumulación de capital; la acumulación máxima de capital que restringe la circulación del dinero y la fuerza de trabajo; la polarización social; y la expansión ilimitada del sistema. ${ }^{29}$

Todas son condiciones que se ajustan al modelo ideal para la auto reproducción del sistema económico imperante que se construye por medio de categóricos discursos, que crean realidades falsas, con el propósito de prolongar su ciclo de vida. Este análisis es visto desde la perspectiva crítica, en el que se involucran diversos elementos que surgen de las relaciones de fuerza entre las clases dominantes y los sujetos.

Como expresamos al inicio, el sistema económico tiene predominancia sobre otros componentes del Estado; es el sistema dominante que utiliza varios mecanismos basados en la autopoiésis que, como afirma Luhmann: "La unidad de un sistema autopoiético no es otra cosa que la reproducción de sus elementos a través de sus elementos. La unidad del sistema económico es el hacer posible pagos a través de pagos. [y que permiten pagos adicionales] Ese es el punto de partida... la manera como el objeto economía produce su propia unidad". ${ }^{30}$

Ahondando en este punto, algunas teorías de análisis científico de la economía tienen sangre frente a la diferencia entre ricos y pobres, diferencia sustentada en una dimensión histórica que más adelante, y resultado del acercamiento de lo social y económico, sostiene que la sociedad como sistema produce la necesidad de esa diferencia, una especie de estratificación social semejante a la necesidad de mantener el orden reproduciendo esa

\footnotetext{
${ }^{29}$ Wallerstein, Immanuel, Análisis de sistemas-mundo. Una introducción. Una introducción, México, Siglo XXI Editores, 2010, pp. 121-122.

${ }^{30}$ Para Luhmann la economía es un sistema cerrado por su circularidad recursiva (los pagos) los elementos del sistema son producidos por elementos del propio sistema, y el entorno no contienen elementos de este tipo; y es abierto al mismo tiempo porque sus operaciones están adaptadas al entorno social y humano acorde a sus necesidades futuras. La autopoiésis es un término que retoma de Humberto Maturana. Véase: Luhmann, Niklas, "La economía de la sociedad como sistema autopoiético", en Revista Mad, Universidad de Chile, núm. 29, septiembre de 2013, pp. 1-25.
} 
diferencia. ${ }^{31}$ Estas ideas necesariamente tienen una estrecha relación en cuanto al discurso de los derechos humanos que forman parte de la dinámica de auto reproducción del mismo sistema. Su esencia es herencia de la doctrina liberal y de los preceptos políticos de la estructura del Estado en la cual el discurso de los derechos humanos se vuelca en el individualismo posesivo y en el derecho a la propiedad privada como medio y fin de una sociedad de mercado. $^{32}$

Vivimos en una sociedad basada en la propiedad privada que el propio Estado de derecho debe proteger. De acuerdo a las ideas de Macpherson, ${ }^{33}$ los derechos humanos son derechos a una vida plena, es decir, derechos de propiedad del individuo. Estos derechos de propiedad no debían contraponerse con la ideología liberal ni con su escala de valores que también sustenta la democracia.

Queda entendido en el derecho internacional que los gobiernos democráticos (republicanos y sustentados en el federalismo) tienen como uno de sus pilares la garantía de los derechos fundamentales y la defensa y protección de los derechos humanos a través de leyes e instituciones creadas ex profeso. No obstante su reconocimiento constitucional y legal en la mayoría de los Estados adscritos a los principales organismos mundiales, como Naciones Unidas, consideraremos al discurso de los derechos humanos como un instrumento de dominación, un dispositivo especializado de control que permite a los gobiernos en turno justificar acciones de injustica y violencia que rebasan sus más esenciales preceptos.

La violación sistemática de los derechos humanos es constantemente registrada por diversos organismos estatales, nacionales e internacionales. Para ilustrar lo dicho, basta mencionar un ejemplo con relación al Informe de Méndez, relator Especial de Naciones Unidas sobre la tortura y otros tratos crueles, inhumanos o degradantes en mayo 2014 en una visita realizada a México. ${ }^{34}$ En primer lugar, reconoce al gobierno mexicano la reforma constitucional de 2011 en materia de derechos humanos que fortalece el sistema de implementación y cumplimiento de las obligaciones internacionales en la materia y refuerza el compromiso de México con la prohibición absoluta de la tortura y los malos tratos. En segundo lugar, su discurso claro y contundente afirma un amplio abanico de acciones realizadas por el Estado que violan casi de forma sistemática los derechos humanos.

\footnotetext{
${ }^{31}$ Luhmann en una crítica a los fisiócratas y a las nuevas corrientes científicas y de reflexión económicas. Ibid., p. 21.

${ }^{32}$ Macpherson, Crawford Brough. Ascenso y caída de la justicia económica y otros ensayos. El papel del Estado, las clases y la propiedad en la democracia del Siglo XX, Argentina, Manantial, 1991.

${ }^{33}$ Ídem.

${ }^{34}$ Conclusiones Preliminares. Visita a México del Relator Especial de Naciones Unidas sobre la tortura y otros tratos crueles, inhumanos o degradantes, Juan E. Méndez, Alan García, Human Rights Watch, de mayo de 2014.
} 
$\mathrm{Al}$ respecto sólo mencionaremos que el relator observa que la Ley Federal para Prevenir y Sancionar la Tortura no refleja completamente la definición de este delito en la Convención de Naciones Unidas contra la tortura; asimismo, esta ley requiere, para sancionar el delito, demostrar la intención respecto al propósito con el que se comete la tortura, lo que es contrario a la definición internacional. También es preocupante que cuando las investigaciones son iniciadas, son extremadamente largas e inconclusas y, en los pocos casos en los que los jueces dan vista al Ministerio Público en conformidad con su obligación jurídica, no suelen darle seguimiento a la investigación, resultando en una mera formalidad.

La aplicación del Protocolo de Estambul ${ }^{35}$ es sesgada y en extremo preocupante, ya que se utiliza como único medio probatorio, llevando a los organismos públicos de derechos humanos, los agentes ministeriales y jueces a concluir que cuando se aplica y resulta negativo, pareciera que la tortura no ha ocurrido. Lo anterior es totalmente contrario al espíritu de este instrumento internacional. Éste debe ser considerado como un elemento probatorio importante; debe ser valorado en conjunto con el resto del acervo probatorio recabado y el contexto de las alegaciones de tortura y malos tratos que argumenta el individuo.

Con estos argumentos, consideramos que el discurso de los derechos humanos es un instrumento de legitimación que se autorreproduce, como una herramienta de regulación ante la criminalidad y ante los grupos vulnerables que pretende compensar la polarización económica y social porque el individuo tiene derechos y libertades que puede ejercer bajo la protección del Estado. No importa la miseria, la exclusión y la falta de justicia, a través de la exigencia de la defensa de los derechos humanos o de la reposición del daño, somos individuos que vivimos bajo un (falaz) Estado de derecho.

Acorde con lo expuesto al inicio, queda claro que en nuestro momento histórico para la sociedad global neoliberal, la acumulación de capital es lo más importante, no el individuo. Parte de los ejes de dominación, se ha comentado, es presentar escindidas áreas esenciales en la construcción de la identidad de los sujetos. Las identidades se forjan fragmentando a los individuos por medio de una despersonalización inducida a través de los discursos ideológicos de forma tal que son construidas para actuar sistémicamente en los sujetos fragmentando su esfera social. El discurso de los derechos humanos es "bueno y bondadoso" porque pretende dar certeza de protección del Estado hacia los individuos. Esta dinámica es fundamental para el sistema neoliberal. Mientras más fragmentada sea la sociedad y el sujeto se individualice pose-

\footnotetext{
${ }^{35}$ Protocolo de Estambul. Manual para la investigación y documentación eficaces de la tortura y otros tratos o penas crueles, inhumanos o degradantes. Serie de Capacitación Profesional número 8, Rev. 1, Oficina del Alto Comisionado de las Naciones Unidas para los Derechos Humanos, onu, Nueva York y Ginebra, 2004.
} 
sivamente, menos podrá integrarse socialmente a un movimiento de lucha activa o de resistencia. Esto conlleva la fragmentación, la desarticulación y el desconocimiento de conflictos comunes que se presentan como conflictos entre particulares, perdiendo su sentido social colectivo.

\section{DEMOCRACIA: ENTRE LA IGUALDAD Y LA LIBERTAD}

Para algunos autores, la democracia de nuestro tiempo está en crisis. Por ejemplo, Ferrajoli ${ }^{36}$ argumenta que el fin de los regímenes comunistas y la crisis ideológica de los partidos de izquierda (al parecer, por dejar de ser alternativas creíbles) dieron cuenta tanto del triunfo del capitalismo como de la liberal-democracia. No obstante, su triunfo se empaña porque cuando la democracia liberal celebra su victoria, se resquebrajan sus elementos constitutivos y se desvanecen sus promesas. Esta crisis simultánea se manifiesta en primer lugar en la "capacidad de representar a la sociedad y realizar la voluntad de la mayoría; en segundo término, la sujeción a la ley de los poderes públicos, el control de legalidad de sus actuaciones y su funcionalización a la tutela y a la satisfacción de los derechos constitucionalmente garantizados". ${ }^{37}$

Conforme a nuestro estudio, pensamos que estos argumentos de Ferrajoli caben en la lógica de Giroux ${ }^{38}$ con la cual coincidimos. Para él, en la época actual, el fundamentalismo del libre mercado es la fuerza conductora de la política y la economía, más que el ideal democrático, incluso, éste en mayor desventaja ya que el capitalismo neoliberal y su ideología de mercado se conduce no sólo por sus beneficios, sino por la asombrosa habilidad para producirse, reproducirse y expandirse. La ideología neoliberal es la piedra angular de los gobiernos democráticos representativos y, por ende, de las sociedades posmodernas. Esto en el entendido de que el neoliberalismo no es sólo una forma económica que rige la economía política y acota las funciones del Estado, es también una "filosofía política e ideológica que afecta todas las dimensiones de la vida social[...] que define al ciudadano como un consumidor, disuelve el contrato social en intereses privados, y separa al capital del contexto de lugar". 39

Estos mecanismos no anulan el discurso de la democracia, por el contario, ella toma otros rostros y paradójicamente se acomoda a la ideología neoliberal

\footnotetext{
${ }^{36}$ Ferrajoli, Luigi. "El Estado constitucional de derecho hoy: el modelo y su divergencia de la realidad", en Ibáñez, Perfecto Andrés (editor). Corrupción y Estado de derecho. El papel de la jurisdicción, Madrid, Trotta, 1996, p. 15.

${ }^{37}$ Ídem.

${ }^{38}$ Giroux, Henry. "Neoliberalismo y la muerte de la Democracia: Resucitando la esperanza en tiempos de oscuridad", Disponible en: http://www.henryagiroux.com/Neo\&Demof\%20Democ_Spanish.htm. [Fecha de consulta: 30 de julio de 2014].

${ }^{39}$ Ídem.
} 
puesto que "el liberalismo se democratizó y la democracia se liberalizó", 40 creando políticas públicas, instituciones y legislaciones que sustentaran la articulación entre democracia y libre mercado bajo la premisa (aparente) de libertad para elegir.

Con estos condicionantes, es obvio que "el vocabulario democrático liberal de derechos, provisiones sociales, comunidad, responsabilidad social, salario digno, seguridad laboral, igualdad, y justicia parecen haber quedado fuera de lugar[... donde la promesa de la democracia ha sido reemplazada por el casino capitalista". ${ }^{41}$

En este sentido, Mouffe afirma que la democracia moderna emana de la articulación de dos tradiciones: la liberal, sustentada en el imperio de la ley, la protección de los derechos humanos y el respeto irrestricto a la libertad individual; y la democrática, sostenida principalmente en la igualdad, la identidad entre gobernantes y gobernados y la defensa de la soberanía popular. ${ }^{42}$ Estas dos tradiciones evidencian las categorías antitéticas de libertad e igualdad. Mientras que la libertad se considera un bien o un fin para el hombre en cuanto a individuo, la igualdad se considera un bien o un fin para el hombre en cuanto ser genérico que tiene un determinado tipo de relaciones entre los integrantes de un todo. ${ }^{43}$

Estas afirmaciones nos conducen a reflexionar sobre los constructos ideológicos del sistema neoliberal. Nunca ha sido fluida y armoniosa la conjunción entre liberalismo y democracia, como tampoco la libertad y la igualdad como componentes de la democracia moderna.

Mouffe analiza estas tensiones de la siguiente manera: Las corrientes dentro de la teoría sobre la democracia tienden a considerarla con una forma que la identifica casi exclusivamente con el Estado de derecho y la defensa de los derechos humanos, obviando la soberanía popular (por ser peligrosa para las instituciones democráticas). De tal forma que la democracia liberal es resultado de la tensión constitutiva entre libertad e igualdad, ambas incompatibles e irreconciliables y cuya tensión puede lograr cierto equilibrio temporal mediante negociaciones pragmáticas entre las fuerzas políticas, pero, al final, con la hegemonía de alguna de ellas. ${ }^{44}$ En esta perspectiva coincidimos con Mouffe cuando afirma:

Desde el punto de vista político, lo que me guía es la convicción de que la incuestionada hegemonía del neoliberal representa una ame-

\footnotetext{
${ }^{40}$ Mouffe citando palabras de C. B. MacPherson, véase: Mouffe, Chantal. La paradoja democrática, España, Gedisa, 2003, p. 20.

${ }^{41}$ Giroux, Henry. "Neoliberalismo y la muerte de la Democracia... op. cit.

${ }^{42}$ Mouffe, Chantal. La paradoja democrática... op. cit., p. 20.

${ }^{43}$ Bobbio, Norberto. Igualdad y Libertad, España, Paidós, 2003, p. 55.

${ }^{44}$ Mouffe, Chantal. La paradoja democrática... op. cit., pp. 21-22.
} 
naza para las instituciones democráticas. Los dogmas neoliberales sobre los inviolables derechos de propiedad, las omnicomprensivas virtudes del mercado, y los peligros de interferir en su lógica, constituyen en nuestros días el «sentido común» imperante en las sociedades liberal-democráticas y están teniendo un profundo impacto en la izquierda, ya que muchos partidos de izquierdas se están desplazando hacia la derecha redefiniéndose eufemísticamente como «centro izquierda». ${ }^{45}$

Cabe decir que la libertad en la democracia sustentada en el Estado de derecho se cobija en el liberalismo, baste recordar que su historia está ligada a la democracia y a la libertad de propiedad. En ello radican las tensiones con la igualdad. Tanto la libertad como la igualdad son deseables en todo régimen político, el punto está en la frase irónica, ya del dominio popular, "Todos somos iguales, pero unos más iguales que otros" que se aplica pragmáticamente en nuestras democracias. Esto trae como consecuencia que existan cada vez más grupos sociales excluidos, y por ende, mayor deslegitimación de las instituciones sociales, y con ellas, las del Estado. La violencia crece, se desborda en sus múltiples manifestaciones. La delincuencia organizada, como el mal de nuestro tiempo, gana amplios espacios territoriales, económicos y, por arrastre, políticos.

\section{EL DERECHO PENAL COMO SÍNTESIS NEOLIBERAL}

Múltiples son las funciones del derecho. Una de ellas, reconocida por los críticos del derecho, es la función de control social. Capella ${ }^{46}$ sostiene que las normas jurídicas producidas por el Estado o por grandes organismos de carácter público tienen un rasgo propio: su producción autoritaria y su capacidad de intervención material en los procesos y las relaciones sociales. Las normas se convierten en técnicas de dominio social constitutivas.

Ya se ha comentado que las normas y los valores que representan son discursos en los que recae la reproducción social; por ello, el Estado y el derecho se constituyen en entes organizados para frenar, controlar y aplicar la violencia. Así, el discurso del derecho es producto de la ideología hegemónica y del discurso del poder "que amenaza con el uso legítimo de la fuerza en caso de no ser obedecido[...] es un sistema comunicativo[...] de carácter coercitivo, cuyo propósito radica en la regulación de ciertos actos y relaciones sociales $[\ldots]$ valiosos[...] para la reproducción social". ${ }^{47}$

\footnotetext{
${ }^{45}$ Ibid., p. 23.

${ }^{46}$ Capella, Juan Ramón, Elementos de análisis jurídico, Madrid, Trotta, 1999.

${ }^{47}$ Nares Rodríguez, Guillermo, Violencia y derechos humanos. Aportes desde el Derecho y las Ciencias Sociales, México, FdCs-BUAP, 2012, p. 15.
} 
A la luz de estos argumentos, retomamos lo dicho al principio sobre los constructos ideológicos eficientes y eficaces para que el sistema dominante mantenga su hegemonía y permita su reproducción, entre los cuales el derecho juega un papel fundamental. Tenemos que "Esta reproducción, al darse en una sociedad en clases, permite que éstas no se eliminen físicamente entre sí, sino que ideológicamente crean la ilusión de colaboración, en pro de una sociedad unificada"48 falazmente. Es lo que Correas llama la «constitución de la conciencia del dominado» incluso como uno de los objetivos políticos más importantes del sentido ideológico del derecho. ${ }^{49}$

Sobre este punto, otra interpretación recae en lo que se denomina «poder blando». Esta expresión fue divulgada por Josep Nye (1990) y explica los mecanismos para aumentar la capacidad de influir en los demás con ciertos fines de «control». La primera es la coacción, la segunda la recompensa y la tercera la atracción: «Es una forma sutil de ejercer el poder[...] Así para lograr la cooperación de los demás, el poder blando persuade con técnicas diferentes de las fuerzas o las del dinero. Más bien aplica ideas como la justicia, los valores compartidos y el deber de contribuir al logro de esos valores». ${ }^{50}$

De hecho, este poder blando se aplica en todas las esferas de la vida humana: económica, empresarial, educativa, religiosa, cultural, etcétera, y por supuesto, en la política. No se contrapone al monopolio de la violencia legítima del Estado. Al ser menos agresivo y directo que el poder duro y el uso de la fuerza, incluso, para las mayorías, es más efectivo; equivale a uno de los constructos ideológicos del poder. Obviamente, los administradores del poder reconocen que parte de los beneficios del control social del derecho es la paz social y lo que conlleva: gobernabilidad y bonanza económica.

Hemos mencionado uno de los objetivos políticos más importantes del derecho, ahora, ya sin ahondar, puesto que lo hemos expuesto, resta enfatizar que el derecho también determina el régimen económico del Estado. La clase gobernante crea derecho y consagra las estructuras económicas de la sociedad" ${ }^{51}$. Esto es perfectamente entendible puesto que "El derecho no tiene valor en sí mismo. No es sino un instrumento al servicio de la clase dominante para realizar los objetivos que esa clase le asigna". ${ }^{52}$

Ahora bien. Vayamos a lo que de forma inherente dentro del derecho se considera por excelencia el sistema punitivo del Estado: el derecho penal. Sobre él, sólo señalamos algunos puntos que sustentan nuestros argumentos.

\footnotetext{
${ }^{48}$ Ídem.

${ }^{49}$ Ibid., p. 17. Citando a O. Correas, 1995.

${ }^{50}$ Scheinsohn, Daniel. El poder y la acción a través de la comunicación estratégica. Hacia una ontología de la estrategia: cómo mover los hilos para que las cosas sucedan, Argentina, Ediciones Granica, 2011, p. 43, quien cita la obra de Josep Nye (1990).

${ }^{51}$ Nares Rodríguez, Guillermo. Violencia y derechos humanos, op. cit., pp. 124-125.

${ }^{52}$ Ibid., p. 124. citando a Diego Cañizares, Fernando (1979).
} 
Cuando hablamos de control social, habrá que determinar qué tipo de control ejerce el derecho y en particular el sistema penal vinculando la idea que por "la carga de legítima violencia estatal que encierra, es la expresión más idónea de un control asumido por el Estado, pero, acordado por la mayoría social". ${ }^{53}$ Estamos hablando del contractualismo (Hobbes, Locke, Rousseau), una larga tradición en la ciencia jurídica y en la ciencia política, que justificaría en buena medida la creación del sistema penal.

Sin entrar en debates, descriptivamente distinguimos en él dos grandes áreas: ${ }^{54}$ la primera, la parte disciplinaria y dogmática, consistente en una descripción abstracta de comportamientos que requieren ser analizados sus elementos constitutivos y componentes que lo integran al resto del sistema jurídico; se trata del sistema penal estático. La segunda, se refiere a la aplicación de los mandatos o prohibiciones producto de las normas penales mismas que se ejecutan a través de instancias como cuerpos policiales, jurisdicción, proceso y cárcel, ejerciendo el control sobre los individuos que realizan conductas previamente definidas como delitos; ello constituye el sistema penal dinámico.

Pero, ¿qué entendemos por delito? (inclusive, por democracia y por derechos humanos) Por ejemplo, en el derecho penal se castiga al delito. La delincuencia es la infracción a la norma penal. Los códigos penales cambian conforme al tiempo y al contexto resultado de múltiples factores, por lo tanto, se trata de un constructo social e histórico. Tanto el delito como el delincuente, lo mismo la democracia y los derechos humanos, no existen objetivamente; su existencia es una existencia social, son constructos sociales que nosotros edificamos, pero, de forma específica, quienes detentan el poder tanto en su forma material, como a través del discurso, y por ende, atravesado y producido por aspectos ideológicos (políticos, económicos, morales, psiquiátricos, etcétera). ${ }^{55}$

Ciertamente, equivale a lo que analiza Foucault en el campo del derecho penal y las formas jurídicas que dan origen a determinadas formas de verdad, con lo cual afirma: “... la constitución de un sujeto que no está dado definitivamente, no es aquello a partir de lo cual la verdad se da en la historia, sino de un sujeto que se constituyó en el interior mismo de ésta y que, a cada instante, es fundado y vuelto a fundar por ella". ${ }^{56}$ Así, enfatiza que las prácticas judiciales son de las prácticas más importantes para construir la emergencia de nuevas subjetividades.

\footnotetext{
${ }^{53}$ Ibid., p. 122.

${ }^{54}$ Ibid., pp. 121-130. Consúltese para una explicación más amplia del sistema penal del Estado moderno.

${ }^{55}$ Consúltese: Ovejero Bernal, Anastasio, Fundamentos de psicología jurídica e investigación criminal, España, Ediciones Universidad de Salamanca, 2006.

${ }^{56}$ Foucault, Michel, La verdady las forma jurídicas, 2ª ed., México, Gedisa, 1986, p. 16.
} 
A pesar de que sea conforme a derecho la aplicación de la norma penal, existe desde tiempos inmemorables el abuso del poder. En una media de opinión sobre la administración y procuración de justicia, el ciudadano común tiene desconfianza hacia la aplicación de la norma, hacia las autoridades y hacia sus instituciones, a pesar del discurso del Estado de derecho y de la protección de los derechos humanos.

Esta preocupación ha sido abordada por destacados juristas. Así, Ferrajoli, en su polémica y discutida teoría sobre el garantismo, propone "un modelo de derecho y una propuesta de teoría general del derecho. El primer supuesto se presenta como una alternativa al Estado de derecho; el segundo, como una superación de los reduccionismos iusnaturalistas y positivistas. Ambos significados confluyen en un axioma distintivo: el derecho como garantía de limitación al poder". ${ }^{57}$ Su aportación al derecho no se circunscribe sólo al derecho penal, sino a todo sistema jurídico, a los derechos fundamentales y a la democracia, temas que también abordó. Un ordenamiento jurídico conformado de acuerdo con las bases institucionales, según Ferrajoli, no significa que sea garantista, porque en él se deben incorporar límites no sólo formales sino también sustanciales al ejercicio de cualquier poder. Como otros juristas, aborda la cuestión de la legalidad y legitimidad, ambas categorías vinculadas con los constructos de dominación. Así refiere que "El principio de mera legalidad se limita en realidad a exigir que el ejercicio de cualquier poder tenga por fuente la ley como condición formal de legitimidad; el principio de estricta legalidad exige por el contrario a la propia ley que condicione a determinados contenidos sustanciales la legitimidad del ejercicio de cualquier poder en ella instituido". ${ }^{58}$

Ciertamente, como observamos desde la perspectiva de la prevención general positiva, el discurso del derecho involucra una validación social teniendo como objetivo la creación y aplicación de la norma. En cuanto al derecho penal, tiene una repercusión tanto política como social. El punto nodal radica en que invariablemente la norma busca adecuar una conducta delictiva al tipo penal; analizado desde la perspectiva teórica del delito, creemos que su legitimación es un acto eminentemente político de validación social ante las exigencias del sistema neoliberal transnacional. Fenómeno jurídico que también se aplica al discurso de los derechos humanos, también visto como un discurso político de legitimación con fines semejantes a los expuestos. Pensamos que en ello radica parte de la síntesis neoliberal del derecho penal.

\footnotetext{
${ }^{57}$ Moreno Cruz, Rodolfo, "El modelo garantista de Luigi Ferrajoli. Lineamientos generales", en Boletín Mexicano de Derecho Comparado, nueva serie, número 120, septiembre-diciembre, 2007, pp. 825-852.

${ }^{58}$ Ferrajoli, Luigi. Derecho y razón... op. cit., p. 857.
} 


\section{ReFLEXIOnes finales}

Desde un perspectiva general y colindando con un enfoque ortodoxo sobre el Estado, éste cumple - entre otras - con la función de ser la principal fuente de los aparatos ideológicos que mantiene viva a una sociedad. En él, y a través de él, se crean, producen y reproducen los constructos ideológicos que permiten la hegemonía del poder. Así, un tanto soterrado, valida a través del derecho las políticas económicas que el sistema neoliberal exige. Funciones más visibles se presentan en la política y en los procesos sociales que tiene que ver con el manejo de las mayorías.

Es así como las políticas económicas que aplica el Estado, paradójicamente, son más cruentas y más afinadas. En el primer sentido porque cada vez es más difícil para el sistema conseguir la acumulación del capital, la depredación de todo el entorno (bienes materiales, hombre, naturaleza) va agotando la vida misma; en el segundo sentido, constantemente debe reformar estructuras del Estado, crear nuevas instituciones, y afinar los mecanismos ilusorios de la democracia debido a la pérdida de legitimidad y al aparente debilitamiento del Estado. En todo este entramado de poder, obvia decir la importancia que juega el derecho en el binomio Estado-economía, articulación que tiene su sustento en sus diferentes ramas disciplinarias.

Mientras, la racionalidad de la ideología neoliberal permanezca y mientras el Estado continúe reduciendo o abandonando partidas presupuestales en política social, generación de empleos e indicadores de desarrollo que impacten sustantivamente en el bienestar público, su función se encaminará cada vez más a desempeños policiales para salvaguardar la seguridad pública, e incluso, la seguridad nacional, resultado de elevados índices de pobreza, exclusión y marginación, aunado a la creciente tendencia de la criminalización de movimientos políticos y sociales más allá del prototipo de conductas desviadas delictivas.

En esta lógica, el derecho en general como sistema de control social, normativo y coactivo, y el sistema penal en particular, se convierten en protectores "legales y legítimos" que mantienen la hegemonía del sistema político-económico. En otras palabras, en tanto más se agudicen los problemas sociales las normas penales provenientes de las políticas criminales serán cada vez más duras y, a contracara, mayores serán los movimientos de resistencia que se generen en el seno de la sociedad.

Finalmente, subrayamos que los constructos ideológicos que crean mecanismos estructurales y sistémicos que permiten la reproducción del paradigma neoliberal, en esencia, conllevan contradicciones, puesto que la democracia se vacía de contenido y de principios, en tanto que se subsume a la lógica del libre mercado sacrificando el equilibrio de sus premisas de igualdad y libertad. Por su parte, los derechos humanos operan bajo esa 
lógica, no simplemente por la adherencia que sostienen con la democracia, sino también porque su protección se asienta en la prevención general positiva en pro de la seguridad pública y seguridad nacional justificando con ello el uso de la violencia de Estado. Por último, el sistema penal crea normas jurídicas a modo; es decir, las conductas criminales a castigar tienen el perfil de ser peligrosas para el mantenimiento del sistema político-económico, obviando las conductas realmente riesgosas que pueden colapsar el sistema, como la pobreza, la marginación, la exclusión y el desempleo; conductas y condiciones de los seres humanos que con acciones concertadas de voluntad política se podrían prevenir. 